\title{
CAPÍTULO 22: INOVAÇÕES EM PROTEÍNAS ALTERNATIVAS: UMA REVISÃO SOBRE ALIMENTOS PLANT-BASED
}

\section{CHAPTER 22: ALTERNATIVE PROTEIN INOVATION: A REVIEW ABOUT PLANT-BASED FOOD}

\author{
Felipe O Giacomelli ${ }^{1}$; Mariana B Pinton ${ }^{2}$; Sarah B S da Silva ${ }^{3}$; Suslin R Thiel ${ }^{4}$; Paulo C B \\ Campagnol $^{5}$
}

\begin{abstract}
Resumo
O aumento de consumo de produtos processados vegetais é uma tendência mundial. Os consumidores escolhem dietas à base de plantas por diversos motivos. Os produtos à base de plantas podem ser benéficos à saúde dependendo da matéria prima base utilizada na formulação, podendo ser classificado até como um alimento funcional. A indústria de análogos da carne começou nos Estados Unidos no século XIX, estabelecendo-se com mais força entre 1970 e 1990, mas no Brasil esta classe de produtos é mais recente. Os primeiros produtos à base de plantas encontrados no Brasil foram as bebidas vegetais (atendendo consumidores com intolerância/alergia a componentes do leite), depois surgiram as carnes de primeira geração. Em sequência surgiram as carnes vegetais de segunda geração e os ovos veganos. Atualmente já existe conhecimento e tecnologia para produzir produtos à base de plantas de forma eficiente e sustentável, atendendo as demandas de crescimento da população sem os efeitos negativos da produção tradicional. O mercado de proteínas alternativas é extremamente promissor, já que existe um aumento na procura de substitutos de carne, com diversas oportunidades de crescimento e sem líderes definidos até o momento.
\end{abstract}

Palavras-Chave: Plant-based, Inovação, carne vegetal, leite vegetal, ovo vegetal.

\begin{abstract}
The increase in consumption of processed vegetable products is a worldwide trend. Consumers choose plant-based diets for a variety of reasons. Plant-based products can be beneficial to health depending on the raw material used in the formulation, and can even be classified as a functional food. The meat analog industry started in the USA in the 19th century, establishing itself more strongly between 1970 and 1990, but in Brazil this class of products is more recent. The first plant-based products found in Brazil were vegetable drinks (serving consumers with intolerance / allergy to milk components), after first-generation meats appeared. In sequence, second generation vegetable meats and vegan eggs appeared. Currently, there is already knowledge and technology to produce plant-based products efficiently and sustainably, meeting the demands of population growth without the negative effects of traditional production. The alternative protein market is extremely promising, since

\begin{tabular}{|c|c|c|c|c|c|c|c|c|c|}
\hline $\begin{array}{l}{ }^{1} \text { Discente do Pro } \\
\text { felipegiacomelli95@ }\end{array}$ & Pós & Graduação & em & iência & e & $\operatorname{logia}$ & & s, & IFS \\
\hline $\begin{array}{l}{ }^{2} \text { Discente do Programa de } \\
\text { mbpinton@gmail.com }\end{array}$ & Pós & $\mathrm{Gr}$ & er & Ciê & e & Tec & em & $\lim$ & UFSM, \\
\hline $\begin{array}{l}{ }^{3} \text { Discente do Programa de } \\
\text { sarahbiancass17@gmail.com }\end{array}$ & Pós & $\mathrm{Gr}$ & $\mathrm{em}$ & ia & $\mathrm{e}$ & Tecr & em & limentos, & \\
\hline $\begin{array}{l}{ }^{4} \text { Discente do Programa de } \\
\text { suslin thiel@ hotmail.com }\end{array}$ & Pós & Gra & em & Clo & & Tec & em & s, & $01 \mathrm{~N}$ \\
\hline $\begin{array}{l}{ }^{5} \text { Docente do Progra } \\
\text { paulocampagnol@gma }\end{array}$ & Pós & 0 & em & $\mathrm{a}$ & & Tecr & $\mathrm{em}$ & Alim & \\
\hline
\end{tabular}
\end{abstract}


there is an increase in the demand for meat substitutes, with several growth opportunities and without defined leaders.

Keywords: Plant-based, Inovation, vegetable meat, vegetable milk, vegetable egg

\section{Introdução}

A substituição de proteína animal por proteínas alternativas é uma opção para os consumidores que se interessam em produtos que ofereçam benefícios à saúde. No entanto, realizar mudanças de dietas a base de carne para produtos plant-based exigirá uma profunda transição social e um desafio árduo (Boer e Aiking, 2017). As práticas alimentares são complexas e influenciadas por diversos fatores de interação, como contexto social, crença, preferências de gosto e tradições culinárias (Hartmann e Sirgrist, 2017).

Os desafios principais são os tecnológicos, a falta de informação e o consumismo. O marketing é um bom aliado para melhorar o consumo desses produtos de origem vegetal, levando a um aumento na procura e desenvolvimento na produção de alternativas à base de carne. A tentativa de simular características sensoriais, como textura e sabor, de produtos cárneos mostra-se difícil, principalmente no que diz respeito à construção de tecido semelhante ao músculo (Sha e Xiong, 2020). O desafio dos processos de estruturação de textura semelhante ao dos produtos cárneos já foi estudado e é bem elucidado no artigo de revisão de Dekkers et al. (2018). De acordo com Graça et al. (2019), sabor, aroma e aparência são fatores que afetam a aceitação e o consumo desses produtos. A inovação na tecnologia de processamento e as formulações criativas de produtos continuarão melhorando as características de qualidade. As inclusões de uma variedade de aditivos, a fim de produzir textura, suculência, sabor à carne, levantam preocupações sobre nutrição, segurança alimentar, rótulo limpo, custo e confiança do consumidor (Sha e Xiong, 2020). Geralmente, os preços de produtos alternativos são mais altos em comparação com produtos cárneos. Isso se deve ao processamento e a alta dependência de ingredientes a aditivos funcionais, apresentando um desafio econômico às indústrias.

O aumento de consumo de produtos processados vegetais é uma tendência mundial. Os consumidores escolhem dietas à base de plantas por diversos motivos, como: saúde (física e mental) (Aydar et al., 2020; Sebastiani et al., 2019; Reipurth et al., 2019), preocupações ambientais (Jansenn et al., 2016), questões éticas e crenças religiosas (Dyett et al., 2013) e gosto pessoal. 
Segundo Jansenn et al. (2016), em uma tabela comparativa de razões para alimentação a base de plantas, o fator saúde foi o apontado como mais importante, uma vez que pode implicar intolerâncias e alergias. Os substitutos de produtos de origem animal são necessários para consumidores que apresentem estas incompatibilidades imunológicas com os compostos do alimento. Segundo uma pesquisa realizada pela Biblioteca Nacional de Medicina dos EUA (2020) houve uma redução na digestão da lactose em $65 \%$ da população mundial. Estudo este corroborado com os dados que cerca de $75 \%$ da população tenha sintomas de intolerância a lactose (Aydar et al., 2020; Silva et al., 2020). Também pode-se relacionar o consumo de produtos de origem animal com a possibilidade de aumento da ocorrência de doenças cardiovasculares e neurodegenerativas (Sarni e Baroni, 2018) e aumento no colesterol (Aydar et al., 2020).

Além dos possíveis problemas que os produtos de origem animal podem causar, os alimentos à base de plantas apresentam muitos benefícios para a saúde, como demonstrado na tabela 1. No entanto, não se deve subestimar a deficiência de micronutrientes essenciais de produtos e dietas à base de plantas que levam ao aumento do risco de desnutrição (Sebastiani et al., 2019).

Tabela 1: Benefícios do consumo de produtos à base de plantas e dietas vegetarianas

\begin{tabular}{ll}
\hline \multicolumn{1}{c}{ Benefício } & \multicolumn{1}{c}{ Referência } \\
\hline Alimento funcional & Omoni \& ALuko, 2005 \\
Alimento nutracêutico & Wang et al., 2015 \\
Melhor perfil lipídico & Berkow \& Barnard, 2005 \\
Redução da pressão arterial & Pistollato et al., 2018 \\
Redução de distúrbios neurodegenerativos & \\
(Alzheimer) & Zujko \& Witkowska, 2014 \\
Rica atividade antioxidante & Aydar et al., 2020 \\
Rico em minerais, fibras e AG insaturados & Snowdon \& Phillips APUD Associação \\
Redução do risco de Diabetes tipo 2 & Dietética Americana, 2009 \\
Redução do colesterol, redução risco de & Rawal et al., 2015 \\
câncer e modulação do sistema imunológico & \\
\hline
\end{tabular}

O objetivo desta revisão é descrever as principais fontes alternativas de proteínas, como "carne" a base de plantas, "leite" e "ovos" vegetais, assim como um breve relato do

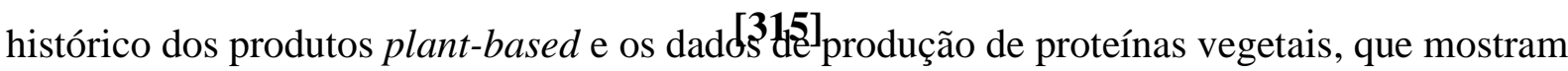


um aumento no interesse e consumo por estes produtos e também que grandes empresas e startups estão desempenhando um papel importante na criação destes alimentos, representando uma menor dependência de animais para a alimentação.

\section{Desenvolvimento}

\section{Históricos de produtos plant-based}

A indústria de "carnes" de origem vegetal nos Estados Unidos remonta ao século XIX (Braun, 2016) e várias das principais empresas de carne à base de plantas foram estabelecidas entre 1970 a 1990. No entanto, o mercado de "carne" de origem vegetal permaneceu pequeno e relativamente estagnado até recentemente, uma vez que foi visto como limitado a veganos e vegetarianos. No entanto, nos últimos anos ocorreu uma grande expansão desse mercado, o que pode ser atribuído a várias razões, incluindo a mudança para biomimética. Essa abordagem para a produção de "carne" através de plantas só começou em 2012 com o lançamento das tiras de frango da empresa Beyond Meat, e decolou com o lançamento de 2016 do "Impossible burger" e do "Beyond Burger", os quais tiveram sucesso nos principais estabelecimentos de fast-food (GFI, 2020).

As cinco maiores empresas de alimentos do mundo desenvolveram mais alimentos à base de plantas nos EUA em 2019. Uma combinação de fatores levou a um mercado em expansão para a "carne" à base de plantas. Entre 2017 e 2019, as vendas no varejo de "carne" à base de plantas cresceram $31 \%$, enquanto as vendas totais de carne no varejo nos EUA cresceram apenas 5\% (GFI, 2020).

As mudanças iniciadas pelo "leite" à base de plantas e impulsionado pela "carne" à base de plantas elevou a indústria de alimentos à base de plantas como um todo, com crescentes categorias, como ovos de origem vegetal que também tiveram um aumento da inovação e crescimento. $\mathrm{O}$ futuro está chegando rapidamente, com as principais empresas de alimentos e produtores de proteínas, como Tyson e Nestlé, fazendo grandes mudanças em alimentos à base de plantas, uma enxurrada de atividades de startups e investidores causaram a aceleração das vendas desses alimentos em 2019 (GFI, 2020).

Para o Brasil, 2019 foi o ano em que ocorreram as grandes mudanças. A Fazenda Futuro iniciou suas atividades em maio. Quase ao mesmo tempo, a startup Behind The Foods iniciou suas atividades no setor. A Superbom, que já operava no mercado, aumentou seu portfólio de produtos e passou a oferecer uma linha de produtos vegetais análogos aos tradicionais. Dando continuidade a esse movimpento de expansão, pouco depois foi lançado o Incrível Burger da Seara Alimentos, que logo se tornou uma linha inteira de produtos, a linha 
Incrível. Também em 2019, a Marfrig lançou um hambúrguer vegetal em parceria com a rede de fast food Burger King e depois anunciou o aumento da sua oferta de produtos vegetais através da marca Revolution. Essa sequência de lançamentos prova que o Brasil é capaz de oferecer soluções no setor de forma rápida e diversificada (GFI Brasil, 2020).

No Brasil, as duas redes varejistas (Extra e Pão de Açúcar) do segmento alimentar que entraram e ofereceram de maneira pioneira as marcas com os primeiros lançamentos de itens plant-based, as vendas dessa categoria de produtos cresceram a uma média constante acima de $150 \%$ desde a segunda quinzena de maio de 2019, data em que teve início a venda do primeiro hambúrguer feito de plantas, significando uma comercialização que quase triplicava a cada mês. Especificamente na linha de hambúrgueres, os produtos feitos com ingredientes à base de plantas consolidaram uma representação de $1 / 3$ da venda bruta total dos hambúrgueres congelados comercializados nacionalmente nas lojas das redes (Agro Planning, 2020).

\section{Dados de produção}

Durante muitos anos, alternativas à base de plantas, tanto para carne, leite e ovos, foram amplamente consideradas de interesse de veganos e vegetarianos. As carnes vegetais surgiram no mercado global como uma alternativa para o consumo de carne. A expectativa é que o produto seja consumido por quem quer diminuir a quantidade de proteína animal ingerida, o que é comumente chamado de "flexitariano" (Freitas, 2020). Ao longo da última década, os principais promotores desses produtos têm impulsionado constantemente as visões da indústria e da mídia popular sobre como será o futuro dos alimentos (Carrington, 2018). Houve investimentos substanciais no desenvolvimento de carnes a base de plantas e cultivadas em laboratório. Esses produtos atraíram investimentos de bilhões de dólares de alguns dos maiores nomes dos negócios globais, incluindo Bill Gates e Richard Branson (Sexton et al., 2019). De acordo com Yaffe-Bellany (2020), muitas das principais empresas de alimentos começaram a investir em carne a base de plantas ou alternativas veganas anos atrás. Mas, o ritmo acelerou nos últimos meses.

Já está em fase de teste uma impressora 3D que produz bifes à base de plantas. Chamada de "Alt-Steak", construída pela startup israelense Redefine Meat. A startup planeja lançar suas impressoras 3D em escala industrial para distribuidores de carne em 2021 (Reuters, 2020). Redes de lanchonetes como a KFC anunciaram uma parceria com a empresa russa 3D Bioprinting Solutions para fabriq3̆ utiliza em sua formulação células de frango em conjunto com material vegetal, sendo assim, 
benéfico ao meio ambiente, por não envolver sacrifício animal. Os testes finais da bioimpressão de nuggets vão ocorrer em Moscou ainda este ano (Fioratti, 2020).

Atualmente, passamos por uma pandemia causada pelo coronavírus SARS-CoV-2, o qual foi identificado em Wuhan na China e causou a COVID-19, sendo em seguida disseminada e transmitida de pessoa a pessoa. Essa situação levou ao aumento da demanda de carnes de origem vegetal. Frigoríficos fecharam quando o coronavírus adoeceu e levou a morte diversos trabalhadores, centenas de lanchonetes ficaram sem matéria-prima para produção de seus hambúrgueres. Essa situação, não diminuiu a demanda por carne nos Estados Unidos. Mas, os problemas nas indústrias de carnes impulsionaram os substitutos de carne à base de plantas, os quais tiveram um salto de $35 \%$ nas vendas durante esse período. Empresas como Impossible Foods e Beyond Meat expandiram suas vendas de forma expressiva com a pandemia. Mesmo antes do coronavírus, o interesse pela carne a base de plantas estava aumentando, mas agora, pela primeira vez, os substitutos feitos com proteínas vegetais estão com preços mais competitivos e mais fáceis de encontrar (Nierenberg, 2020). Na figura 1, é mostrado como as vendas de alimentos dispararam durante a pandemia. Podese observar que a taxa de vendas de carne foi superada pela das alternativas baseadas em plantas.

Figura 1: Aumento de vendas de carne a base de plantas

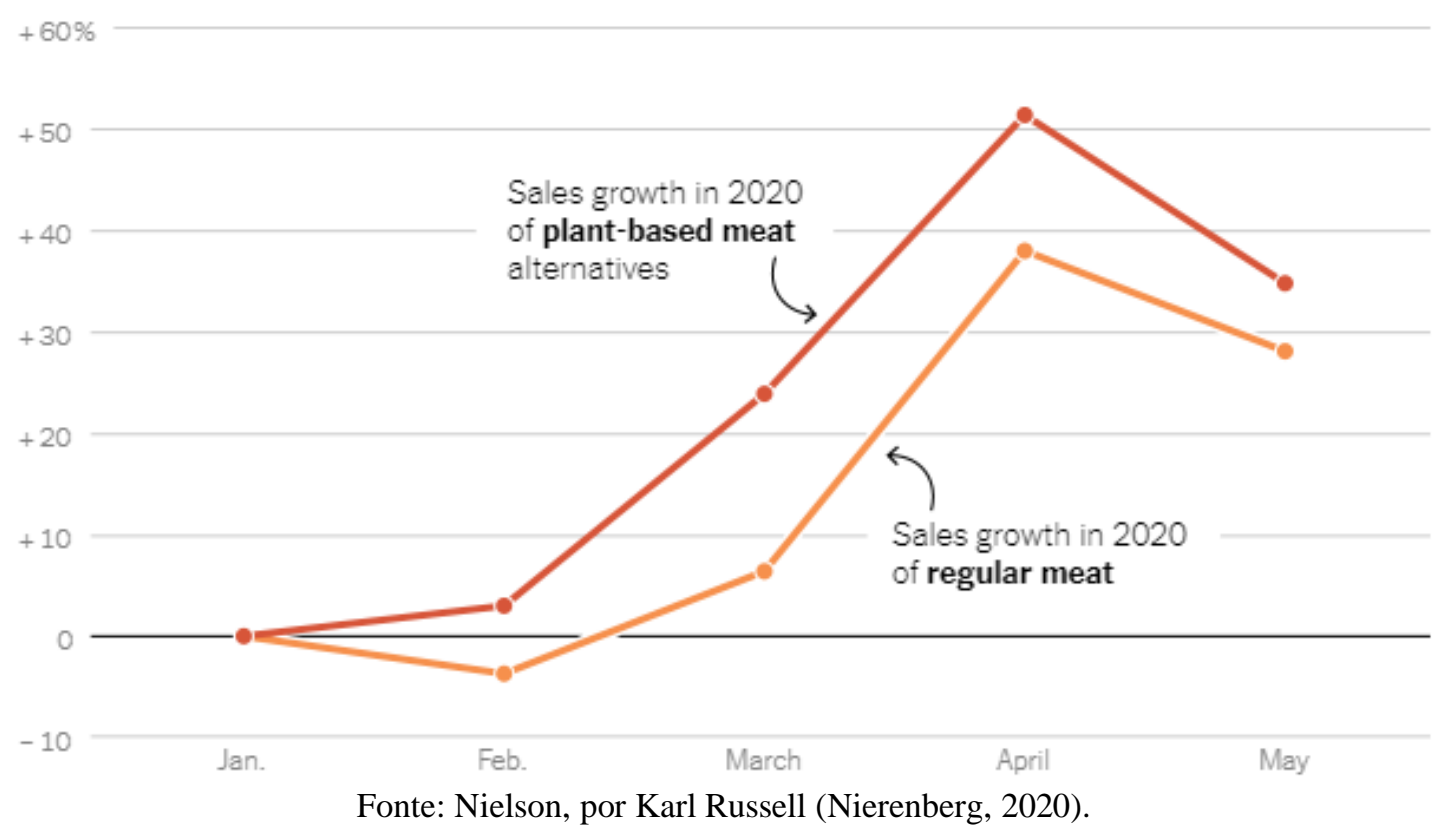

De 2015 a 2019, a busca por "carne vegetal" por brasileiros, na plataforma Google, aumentou $150 \%$. De acordo com a pesquis $[3 \mathbf{3} 5 \mathbf{5}] \%$ dos 4.335 respondentes, estão dispostos a reduzir o consumo de carne pelo menos uma vez por semana (Freitas, 2020). A startup 
Fazenda Futuro surgiu no Rio de Janeiro com a proposta de desenvolver alimentos somente com ingredientes à base de plantas, que emulam o gosto, textura e suculência da carne animal (Oliveira, 2020). O fundador da Fazenda Futuro, Marcos Leta, comenta no anúncio da foodtech que "o objetivo é liderar a transformação em uma categoria que nunca trouxe inovação ao consumidor, e trabalhar com tecnologia e propósito sem causar um impacto negativo ao meio ambiente". Com isso, a startup se lançou no mercado brasileiro e europeu com produtos à base de vegetais como carne moída, hambúrgueres, almondegas, linguiças, todos equivalentes aos produtos cárneos. Atualmente, vem expandindo sua atuação pelo mundo. Após expandir para outros países da América Latina, chegou em fevereiro de 2020, a Holanda. E, em julho, começou a exportação de sua carne vegetal para os Emirados Árabes, sendo vendida por meio de e-commerce em Dubai (Oliveira, 2020). A Fazenda Futuro é líder do mercado brasileiro no ramo de carne vegetal. Mas, não está livre de concorrências. A NotCo, startup chilena, produz diversos alimentos feitos de plantas e irá lançar o seu "nãohambúrguer" no Brasil, ainda este ano (Freitas, 2020). A empresa norte-americana Beyond Meat está chegando ao mercado brasileiro com quatro produtos à base de plantas, hambúrgueres, carne moída e dois tipos diferentes de linguiças (Delorenzo, 2020).

Buscar alternativas para driblar o consumo excessivo de carne é uma tendência que veio para ficar. Até 2050, o mundo precisará alimentar 10 bilhões de pessoas e produzir o dobro de proteína (Godfray et al., 2019). Embora a carne seja uma fonte comum de proteínas, métodos convencionais de produção são insustentáveis. Estima-se que a produção pecuária seja responsável por $14,5 \%$ das emissões de gases do efeito estufa, assim como, um dos maiores usuários industriais de água e terra (Gerber et al., 2013). As proteínas alternativas representam uma ampla categoria de produtos que ecoam no movimento em direção a menor dependência de animais para alimentação (Ong et al., 2020). Análises de ciclo de vida ambiental constatam que as carnes de origem vegetal e cultivadas terão emissões de gases de efeito estufa drasticamente mais baixas em relação à carne bovina ou de aves cultivadas em fazendas (Mattick et al., 2015).

\section{Fontes alternativas de proteínas}

A produção contemporânea de alimentos de origem animal tem sofrido muitas críticas negativas devido os impactos que causam na esfera ambiental, da saúde e de bem-estar animal (Trusts \& Hopkins, 2008). Em resposta a estas questões, com inovação tecnológica e investimentos financeiros, foram lançados p[319]os de proteínas alternativas (Broad, 2019). 
A inovação começou de forma inexpressiva com a primeira geração de produtos à base de plantas, que buscavam oferecer alternativas aos produtos de origem animal (hambúrgueres de soja, proteína texturizada de soja (PTS) e leites vegetais) principalmente aos consumidores com restrição alimentar (GFI, 2020). Os avanços em ciência de alimentos (tecnologia de sabores e processos de extrusão) levaram a uma capacidade aprimorada de criar alimentos à base de plantas que imitam os produtos animais originais (Broad, 2019).

\section{Carnes a base de Plantas}

Os análogos de carne à base de plantas têm uma longa história na culinária cultural global e, nas últimas décadas, foram produzidos em massa e comercializados diretamente para principalmente consumidores vegetarianos, ocupando um nicho atraente em restaurantes e lojas (Broad, 2020). Estes produtos análogos aos tradicionais (a base de carne) são produzidos com a combinação de matéria prima vegetal (grãos, frutas, tubérculos, raízes tuberosas, entre outros) aromas para imitar o sabor e a textura de produtos animais existentes através de uma abordagem biomimética (GFI, 2020a) ou ainda por rota biotecnológica (agricultura celular) que isola células animais e desenvolve as chamadas carnes cultivadas (Mouat et al., 2019).

Grande parte dos produtos à base de plantas encontrados no Brasil atualmente, são produzidos a partir de soja nacional ou ervilha importada. Considerando o crescimento previsto para o mercado de proteínas alternativas, será necessário não apenas aumentar a oferta desses produtos como também diversificar a opção de proteínas em suas composições (GFI, 2020; Godfray, 2019; Broad, 2019; Broad, 2020). Na tabela 2 encontram-se as "carnes vegetais" comercializadas atualmente no Brasil. 
Tabela 2: Produtos à base de plantas industrializados no Brasil

\begin{tabular}{|c|c|}
\hline Produto análogo & Empresa produtora \\
\hline \multirow{10}{*}{ Hambúrguer } & Behind the Foods; \\
\hline & $B R F$ \\
\hline & Fazenda Futuro; \\
\hline & Goshen; \\
\hline & $J B S$ \\
\hline & Marfrig; \\
\hline & Sotille; \\
\hline & Superbom; \\
\hline & The New Butchers; \\
\hline & Vegabom \\
\hline \multirow{2}{*}{$\begin{array}{l}\text { Almôndega } \\
\text { Carne Moída }\end{array}$} & Fazenda Futuro \\
\hline & Fazenda Futuro; \\
\hline \multirow{3}{*}{ Linguiças } & Goshen; \\
\hline & Superbom; \\
\hline & Vegabom \\
\hline \multirow{2}{*}{ Embutidos Fatiados } & Goshen; \\
\hline & Superbom \\
\hline \multirow{2}{*}{ Nuggets } & $B R F$ \\
\hline & $J B S$ \\
\hline \multirow[t]{2}{*}{ Tiras de Frango } & The New Butchers \\
\hline & Goshen; \\
\hline \multirow[t]{2}{*}{ Empanados } & Superbom; \\
\hline & Vegabom \\
\hline
\end{tabular}

Fonte: adaptado de GFI Brasil, 2020

A produção de carne à base de plantas ainda é realizada em sua maioria a partir da técnica de extrusão, mas já existem outros métodos (tecnologia de células Couette (cisalhamento) e a impressão 3D) sendo estudados e avançando para soluções viáveis em qualidade e capacidade de produção (GFI, 2020b).

Estudos mais avançados sobre texturização de proteínas permitiu que produtos de carne reestruturados progredissem de "migalhas" (usadas em hambúrgueres) a pedaços e 
pedaços cortados em cubos, oferecendo maior versatilidade para produção de produtos à base de "carne vegetal". Embora o sabor e a textura da carne à base de plantas sejam os principais motivos para atrair o consumidor, as inovações projetam produtos que realmente imitem a experiência completa da carne (da aparência "ao ponto" até ao aroma característico) (GFI, 2020b). O aroma tem sido estudado através da separação por cromatografia gasosa, onde identifica-se os "aromas essenciais da carne". Como o aroma característico é transformado durante a cocção, ainda não foi possível encontrar os precursores certos para as carnes vegetais (Jacobsen, 2016).

\section{5 "Leites" vegetais}

Em vista da crescente demanda por produtos e derivados sem leite no mercado mundial, o desenvolvimento de novos produtos é de primordial importância para as empresas, pois esses novos produtos estão diretamente relacionados às necessidades e tendências de consumo da população (Silva et al., 2020).

A demanda do consumidor por alternativas ao leite de vaca aumentou como resultado de pessoas serem intolerantes ao leite de vaca, incluindo intolerância à lactose e alergia ao leite de vaca (Jeske et al., 2018), além de estilos de vida como o vegetarianismo e o veganismo. A estratégia usada por esses indivíduos e pela indústria de alimentos tem sido o "leite" à base de plantas. Porém, é essencial mencionar que existem alternativas para indivíduos com intolerância à lactose, como produtos sem lactose e o uso da enzima lactase, no entanto, para indivíduos alérgicos e veganos, a única opção é o "leite" à base de plantas (Vanga \& Raghavan, 2018).

A bebida à base de plantas mais consumida é a de soja. No entanto, o consumo deste produto é limitado pela alergia à soja, que afeta cerca de $0,5 \%$ da população em geral (Katz et al., 2014), apesar de existirem também alergias em relação a outras oleaginosas, portanto, são necessárias outras alternativas para atender este público.

De acordo com Aydar et al. (2020), Pineli et al., (2015) e Wang et al. (2018), existem diversos substitutos, como amêndoa, caju, coco, avelã, amendoim, gergelim, porca de tigre, aveia, arroz, cânhamo, nozes, quinoa e grão de bico. No entanto, estes possuem características sensoriais, estabilidade e composição nutricional diferentes do leite de vaca (Sethi et al., 2016) principalmente em relação ao teor de proteínas, gorduras e minerais. Na tabela 3 a seguir são mostradas diferentes bebidas à base de plantas e seu respectivo valor nutricional em relação ao teor de proteína, gordura e cinzas. 
Tabela 3: Valor nutricional proteína, gordura e cinzas $(\mathrm{g} / 100 \mathrm{~g})$ de diferentes bebidas à base de plantas.

\begin{tabular}{|c|c|c|c|c|}
\hline Bebidas vegetais & Proteína & Gordura & Cinzas & Autor \\
\hline Grão de bico & $1,21 \pm 0,01$ & $0,34 \pm 0,01$ & $0,15 \pm 0,00$ & Wang et al., \\
\hline Soja amarela & $2,09 \pm 0,01$ & $0,74 \pm 0,02$ & $0,22 \pm 0,01$ & 2018. \\
\hline Amêndoa (Marca 1) & $2,11 \pm 0,09$ & $4,40 \pm 0,11$ & $0,35 \pm 0,04$ & \multirow{16}{*}{$\begin{array}{c}\text { Jeske et al., } \\
2017\end{array}$} \\
\hline Amêndoa (Marca 2) & $0,41 \pm 0,02$ & $1,18 \pm 0,05$ & $0,55 \pm 0,00$ & \\
\hline Amêndoa (Marca 3) & $0,95 \pm 0,39$ & $3,69 \pm 0,11$ & $0,21 \pm 0,02$ & \\
\hline Caju & $0,87 \pm 0,10$ & $2,50 \pm 0,10$ & $0,23 \pm 0,01$ & \\
\hline Coco & $0,08 \pm 0,00$ & $0,84 \pm 0,00$ & $0,52 \pm 0,01$ & \\
\hline Avelã & $0,36 \pm 0,00$ & $1,56 \pm 0,05$ & $0,52 \pm 0,00$ & \\
\hline Cânhamo & $0,08 \pm 0,04$ & $2,44 \pm 0,23$ & $0,42 \pm 0,01$ & \\
\hline Macadâmia & $0,29 \pm 0,01$ & $2,62 \pm 0,06$ & $0,25 \pm 0,01$ & \\
\hline Aveia & $0,70 \pm 0,19$ & $0,38 \pm 0,06$ & $0,2 \pm 0,00$ & \\
\hline Quinoa & $0,22 \pm 0,04$ & $2,32 \pm 0,13$ & $0,17 \pm 0,01$ & \\
\hline Arroz & $0,32 \pm 0,04$ & $0,85 \pm 0,06$ & $0,14 \pm 0,02$ & \\
\hline \multirow[t]{2}{*}{ Arroz escuro } & $0,07 \pm 0,00$ & $0,95 \pm 0,04$ & 0,10 & \\
\hline & & & 0,010 & \\
\hline Soja & $2,72 \pm 0,06$ & $2,11 \pm 0,04$ & $0,61 \pm 0,04$ & \\
\hline Soja (UHT) & $3,70 \pm 0,03$ & $2,04 \pm 0,11$ & $0,34 \pm 0,02$ & \\
\hline Leite pasteurizado & $3,70 \pm 0,14$ & $3,28 \pm 0,05$ & $0,62 \pm 0,01$ & \\
\hline Grão de bico & $2,1 \pm 0,07$ & $0,39 \pm 0,2$ & $0,37 \pm 0,11$ & \multirow{6}{*}{$\begin{array}{c}\text { Rincon et al., } \\
2020\end{array}$} \\
\hline Coco & $1,04 \pm 0,31$ & $7,42 \pm 1,68$ & $0,32 \pm 0,09$ & \\
\hline $90 \%$ Grão de bico e $10 \%$ coco & $2,09 \pm 0,16$ & $1,08 \pm 0,28$ & $0,4 \pm 0,11$ & \\
\hline $80 \%$ Grão de bico e $20 \%$ coco & $1,96 \pm 0,07$ & $1,74 \pm 0,35$ & $0,33 \pm 0,05$ & \\
\hline $70 \%$ Grão de bico e $30 \%$ coco & $1,9 \pm 0,18$ & $3,25 \pm 1,15$ & $0,32 \pm 0,08$ & \\
\hline $50 \%$ Grão de bico e $50 \%$ coco & $1,54 \pm 0,09$ & $3,43 \pm 0,38$ & $0,33 \pm 0,07$ & \\
\hline Quinoa & $1,7 \pm 0,01$ & $0,2 \pm 0,1$ & - & Pineli et al., \\
\hline Arroz & $0,30 \pm, 036$ & $1,11 \pm 0,35$ & - & 2015 \\
\hline
\end{tabular}

Jeske et al. (2017), analisaram diferentes marcas disponíveis comercialmente, já os autores Wang et al. (2018), Rincon et al. (2020) e Pineli et al. (2015), produziram as bebidas vegetais. Em relação a tabela 3, analisando os dados pode-se perceber grandes diferenças para 
os teores de proteínas, gorduras e cinzas entre todas as bebidas vegetais. Houve uma discrepância nos teores para a mesma oleaginosa, por exemplo a amêndoa.

A soja é a oleaginosa que se destaca em relação às demais mencionadas na tabela 3. É a bebida vegetal que mais se assemelha pela quantidade de proteínas do leite de vaca, no entanto, conforme estudo de Vasconcelos et al. (2006), a soja não possui dois aminoácidos essenciais (metionina e fenilalanina) ao contrário do leite de vaca.

A falta de aminoácidos essenciais em vegetais é um dos grandes problemas, o grão de bico, ervilha, feijão, quinoa, linhaça, cânhamo e tremoço não possuem o aminoácido essencial triptofano (Sánchez-Vioque et al. 1999; Chan e Phillips, 1994; Mattila et al. 2018). Outras fontes também não possuem alguns aminoácidos não essenciais como a cisteína e a tirosina em soja, prolina em grão de bico e cisteína em ervilha (Vasconcelos et al., 2006; SánchezVioque et al. 1999; Chan e Phillips, 1994). Rincon et al. (2020) produziram bebidas vegetais através de diferentes formulações com grão de bico e coco, o que pode ser interessante para promover um equilíbrio em relação aos nutrientes. No entanto, ainda existem poucos estudos na literatura.

Em relação ao conteúdo de cinzas, a bebida vegetal de soja possui uma quantidade similar que o leite de vaca, porém, o seu conteúdo de cálcio é 10 vezes menor que o leite de vaca integral (TACO, 2011). Entanto, uma alternativa seria promover o enriquecimento de cálcio em bebidas vegetais (Casé et al., 2005). Porém, a sedimentação do cálcio adicionado ainda permanece um problema, pois foi demonstrado que as bebidas de soja fortificada com cálcio não sacudido atingiram em média apenas $31 \%$ de sua reivindicação no rótulo e apenas 59\% quando sacudidas (Heaney \& Rafferty, 2006). Já o conteúdo de magnésio em leite integral e desnatado de vaca é de $10 \mathrm{mg} / 100 \mathrm{~mL}$ e na bebida de soja é em torno de $15 \mathrm{mg}$ /100 mL (TACO, 2011).

Os vários componentes bioativos presentes nas plantas que impactam a absorção de nutrientes também merecem discussão. $\mathrm{O}$ ácido fítico está presente em muitos cereais e leguminosas e é descrito como um anti-nutriente devido à sua capacidade de se ligar a minerais essenciais e oligoelementos (incluindo cálcio, zinco, ferro, magnésio e cobre) para criar complexos insolúveis desses minerais que inibem sua absorção no intestino. A presença de ácido fítico natural diminui a biodisponibilidade do cálcio da farinha de arroz, farinha de soja para 46,53\%, 10,70\% e 3,77\%, respectivamente (Dendougui \& Schwedt, 2004). São necessárias mais pesquisas para quantificar com mais precisão o efeito de anti-nutrientes e baixa resolubilização do cálcio na absorção total de cálcio de alternativas comuns ao leite à base de plantas (Chalupa-Krebzdak et al., 2018). 
Cabe destacar, no entanto, que as bebidas vegetais contêm componentes funcionalmente ativos com propriedades promotoras da saúde que atraem consumidores preocupados com a saúde (Sethi et al., 2016). Compostos fenólicos, ácidos graxos insaturados, atividade antioxidante e compostos bioativos como fitoesteróis e isoflavonas tornam os substitutos do leite à base de plantas uma excelente opção (Aydar et al., 2020). As bebidas obtidas a base de vegetais são ricas em antioxidantes que reduzem o risco de doenças cardiovasculares, câncer, aterosclerose e diabetes, impedindo que os radicais livres oxidem ácidos nucleicos, proteínas, lipídios e DNA (Maleki et al., 2015). Vinson \& Cai (2012), analisaram os níveis de polifenóis livres e totais em amêndoa, castanha do Brasil, caju, macadâmia, amendoim, nozes, pistache e nozes, e todas apresentaram uma alta concentração, que variou entre 11,1 a $107 \mu \mathrm{mol}$ de catequina / g. É importante ressaltar, no entanto, que parte desses compostos bioativos benéficos à saúde são perdidos durante o processamento (Aydar et al., 2020).

O grande desafio da indústria, no entanto, é produzir bebidas vegetais com características sensoriais similares ao leite de vaca. Isto possibilitará atingir um novo mercado, que é atualmente composto quase em sua totalidade por consumidores que possuem intolerâncias e alergias ao leite de vaca ou que não consomem produtos de origem animal.

\section{“Ovos" vegetais}

O ovo plant-based é um produto à base de plantas que substitui o ovo convencional proporcionando a mesma textura e sabor. O ovo plat-based oferece as mesmas vantagens do ovo convencional podendo ser usado na elaboração de produtos de panificação e em outros setores. Ele é produzido com a combinação de ingredientes vegetais como amido de batata, farinha de tapioca, bicarbonato de sódio, fibra de casca de psyllium, tofu de seda, entre outros. É uma opção ideal para o público vegano, vegetariano, ovolactovegetariano e para indivíduos intolerantes ou alérgicos ao ovo. Além disto, tem como vantagens em relação ao ovo tradicional a maior vida útil, a maior facilidade para transporte e armazenagem e além disso, possui uma maior segurança microbiológica (Gonçalves, 2019).

Várias indústrias estão se adequando a nova demanda dos consumidores, com isso podemos esperar diversas opções de ovo plant-based. Por exemplo, a JUST é uma empresa americana que produz um ovo líquido planted-based que tem como ingrediente principal a proteína de feijão mungo (Guerrero, 2018). Outro exemplo é a empresa Mantiqueira, que é a maior produtora de ovo convencional do Brasil. Esta empresa lançou a sua primeira formulação de ovo plant-based em pó, o qual contém proteína de ervilha, amido de ervilha e 
linhaça dourada. Esse ingrediente tem características muito similares a um ovo convencional quando adicionado de água, podendo ser utilizado para a elaboração de bolos e pães sem afetar a qualidade tecnológica e sensorial dos produtos (Mantiqueira, 2019). Já a startup americana de tecnologia Clara Foods pretende lançar claras de ovos plant-based produzidas à partir de leveduras de cerveja e açúcar (Ata News, 2018).

\section{Considerações Finais}

Segundo dados da $F A O / O N U$ a demanda da agricultura precisa aumentar em quase $50 \%$ para suprir as necessidades de alimentos da população em 2050, levando em consideração a projeção que seremos 9,7 bilhões de pessoas no planeta. A produção de produtos à base de plantas é mais sustentável que a produção tradicional, principalmente para as carnes vegetais, apresentando-se como uma ótima alternativa de proteína análoga. As indústrias de alimentos estão em constante inovação, uma vez que os consumidores sempre buscam novos produtos. Nos últimos anos notou-se um aumento nos produtos anunciados como veganos, sem laticínios e éticos (o que significa que os produtores não contribuem para a crueldade animal). À medida que novas tendências crescem, o cenário se torna mais competitivo com a presença de produtos adicionais.

\section{Referências}

AGRO PLANNING. Em um ano, alimentos plant-based se consolidam no cardápio do consumidor brasileiro. 2020.2 Disponível em: https://www.agroplanning.com.br/2020/07/06/em-um-ano-alimentos-plant-based-seconsolidam-no-cardapio-do-consumidor-brasileiro/. Acesso em: 28 de julho 2020.

AIKING, Harry. Future protein supply. Trends in Food Science \& Technology, v. 22, n. 23, p. 112-120, 2011.

ASSOCIAÇÃO DIETÉTICA AMERICANA. Position of the American Dietetic Association: Vegetarian diets. J. Amer. Diet. Assoc. v. 109, p. 1266-1282, 2009.

AYDAR, E.F.; TUTUNCU, S.; OZCELIK, Be.. Plant-based milk substitutes: Bioactive compounds, conventional and novel processes, bioavailability studies, and health effects. Journal of Functional Foods, v. 70, p. 103975, 2020.

BERKOW, S.E.; BARNARD, N.D. Blood pressure regulation and vegetarian diets. Nutrition reviews, v. 63, n. 1, p. 1-8, 2005.

BIBLIOTECA NACIOANL DE MEDICINA DOS EUA. Lactose intolerance. Genetics Home Reference. Acesso em: 25 de julho de 2020 <https://ghr.nlm.nih.gov/condition/lactoseintolerance>. 
BOER, J.; AIKING, H.. Pursuing a low meat diet to improve both health and sustainability: How can we use the frames that shape our meals?. Ecological economics, v. 142, p. 238-248, 2017.

BRAUN, W. Meat analogues: Just like your adventist mother used to make. 2016. Disponível em: ttps://www.huffpost.com/entry/meat-analogues-just-

BROAD, G.M. Making Meat, Better: The Metaphors of Plant-Based and Cell-Based Meat Innovation. Environmental Communication, p. 1-14, 2020.

BROAD, G.M. Plant-based and cell-based animal product alternatives: an assessment and agenda for food tech justice. Geoforum, v. 107, p. 223-226, 2019.

CARAZZAI, Estelita Hass. Trump agora promete acabar com política que separa famílias de refugiados. Folha de S.Paulo, São Paulo, 20 de jun. de 2018. Disponível em: <https://www1.folha.uol.com.br/mundo/2018/06/trump-agora-promete-acabar-com-politicaque-separa-familias-de-refugiados.shtml>. Acesso em: 20 de jun. de 2018.

CARRINGTON D. 2018. The new food: meet the startups racing to reinvent the meal. Guardian. Acesso: www.theguardian.com/environment/2018/apr/30/lab-grown-meat-how-abunch-of-geeksscared-the-meat-industry, acesso 25, julho, 2020.

CASÉ, F.; DEliZA, R.; ROSENTHAL, A.; MONTOVANI, D.; FERBERG, I. 2005. Produção de "leite" de soja enriquecido com cálcio. Ciência Tecnologia Alimentos, v.25. p. 86-91, 2005.

CHALUPA-KREBZDAK, S.; LONG, C.J.; BOHRER, B.M. Nutrient density and nutritional value of milk and plant-based milk alternatives. International dairy journal, v. 87, p. 84-92, 2018.

CHAN, C.; PHILLIPS, R. D. Amino acid composition and subunit constitution of protein fractions from cowpea (Vigna unguiculata L. Walp) seeds. Journal of Agricultural and Food Chemistry, v.42. p. 1857-1860, 1994.

CROWE, F. L.; APPLEBY, P. N.; TRAVIS, R. C.; KEY, T. J. Risk of hospitalization or death from ischemic heart disease among British vegetarians and nonvegetarians: Results from the EPIC-Oxford cohort study. Am. J. Clin. Nutr. v. 97. p.597-603, 2013.

DEKKERS, B. L.; BOOM, R. M.; VAN DER GOOT, A. J. 2018. Structuring process for meat analogues. Trends in Food Science \& Technology, v.81, p. 25 - 36.

DENDOUGUI, F.; SCHWEDT, G. 2004. In vitro analysis of binding capacities of calcium to phytic acid in different food samples. European Food Research and Technology, v.219. p. 409-415, 2004.

Do que é feito o N.ovo. Mantiqueira, 2019. Disponivel em : https://www.ovosmantiqueira.com.br/conheca-o-n-ovo?localidade=sp 
DYETT, P.A.; SABATÉ, J.; HADAD, E.; RAJARAM, S.; SHAVLIK, D.. Vegan lifestyle behaviors. An exploration of congruence with health-related beliefs and assessed health indices. Appetite, v. 67, p. 119-124, 2013.

Empresa investe na criação de "claras de ovos" veganas. Ata News, 2018. Disponive em: https://atanews.com.br/noticia/8312/empresa-investe-na-criacao-de--claras-de-ovos--veganas

FIORATII, C. 2020. KFC pretende vender nuggets produzidos por bioimpressão 3D. Acesso: https://super.abril.com.br/ciencia/kfc-pretende-vender-nuggets-produzidos-por-bioimpressao3d/, Acesso dia 25 julho, 2020.

FREITAS, T. 2020. Brasileiros pesquisam 150\% mais "carne vegetal". Acesso: https://www.startse.com/noticia/startups/brasileiros-carne-vegetal-fazenda-futuro, Acesso dia 25 julho, 2020.

GERBER, P.J. et al., 2013. Tackling climate change through livestock - A global assessment of emissions and mitigation opportunities. Food and Agriculture Organization of the United Nations (FAO), Rome.

GFI BRASIL. Industria de Proteínas Alternativas. 2020. Disponível em: https://gfi.org.br/wp-content/uploads/2020/06/GFI_2020_IndProtAlternativas.pdf. Acesso em: 28 de julho 2020.

GFI. The Good Food Institute. 2019 U.S. State of the Industry Report Plant-Based Meat, Eggs,and Dairy. 2020. Disponível em: https://www.gfi.org/files/soti/INN-PBMED-SOTIR2020-0507.pdf. Acesso em: 28 de julho 2020.

GODFRAY, H. C. J. et al. Meat: the future series Alternative Proteins. In: World Economic Forum. 2019.

GONÇALVES, F. N. A crescente demanda por ovo vegano. Vegan Business, 3 de setembro de 2019. Disponivel em: https://veganbusiness.com.br/a-crescente-demanda-por-ovo-vegano/

GRAÇA, J.; GODINHO, C.A.; TRUNINGER, M.. Reducing meat consumption and following plant-based diets: Current evidence and future directions to inform integrated transitions. Trends in Food Science \& Technology, v. 91, p. 380-390, 2019.

GUERRERO, C. J. San Francisco company makes vegan scrambled egg substitute that tastes like real eggs. ABC news, EUA, 21 de julho de 2018. Disponivel em: https://abc7news.com/eggs-egg-substitute-perfect-scrambled-mung-bean/3795652/

HARTMANN, C.; SIEGRIST, M. Consumer perception and behaviour regarding sustainable protein consumption: A systematic review. Trends in Food Science \& Technology, v. 61, p. 11-25, 2017.

HEANEY, R. P.; RAFFERTY, K. 2006. The settling problem in calcium-fortified soybean drinks. Journal of the American Dietetic Association, v.106. p. 1793, 2006. 
HERRERO, M. Feeding the planet: key challenges. In: Energy and protein metabolism and nutrition in sustainable animal production. Wageningen Academic Publishers, Wageningen, 2013. p. 27-34..

JACOBSEN, R. The biography of a plant-based burger. Pacific Standard, 2016. Acesso em 28/07/2020 em < https://psmag.com/news/the-biography-of-a-plant-based-burger>.

JANSSEN, M; BUSCH, C.; RODIGER, M.; HAMM, U.. Motives of consumers following a vegan diet and their attitudes towards animal agriculture. Appetite, v. 105, p. 643-651, 2016.

JESKE, S.; ZANNINI, E.; ARENDT, E. K. 2017. Evaluation of Physicochemical and Glycaemic Properties of Commercial Plant-Based Milk Substitutes. Plant Foods Hum Nutr, v. 72. p. 26-33, 2017.

JESKE, S.; ZANNINI, E.; ARENDT, E.K. Past, present and future: The strength of plantbased dairy substitutes based on gluten-free raw materials. Food research international, v. 110, p. 42-51, 2018.

KATZ, Y.; GUTIERREZ-CASTRELLOM, P.; GONZÁLEZ, M. G.; RIVAS, R.; LEE, B. W.; ALARCON, P. 2014. A comprehensive review of sensitization and allergy to soy-based products. Clinical Reviews in Allergy and Immunology, v.46. p. 272-281, 2014.

MALEKI, N.; KHODAIYAN, F.; MOUSAVI, S. M. 2015. Antioxidant activity of fermented Hazelnut milk. Food Science and Biotechnology, v.24. p. 107-115, 2015.

Mantiqueira lança ovo vegano. 9 de maio de 2019.Disponível em: https://www.aviculturaindustrial.com.br/imprensa/mantiqueira-lanca-ovo-vegano/20190509$\underline{150519-\mathrm{m} 392}$

MATILLA, P.; MAKINEN, S.; EUROLA, M.; JALAVA, T.; PIHLAVA, J. M.; HELlSTROM, J.; PIHLANTO, A. 2018. Nutritional Value of Commercial Protein-Rich Plant Products. Plant Foods for Human Nutrition, v. 73. p.108-115, 2018.

MATTICK, C. S.; LANDIS, A. E.; ALlENBY, B. R. 2015. A case for systemic environmental analysus of cultured meat. Journal of Integrative Agriculture, v. 15, -. 249 254.

MICHA, R.; PEÑALV, J. L; CUDHEA, F.; IMAMURA, F.; Rehm, C. D.; MOZAFFARIAN, D. 2017. Association between dietary factors and mortality from heart disease, stroke, and type 2 diabetes in the United States. JAM,. v. 317. p. 912-924, 2017.

MOUAT, M.J.; PRINCE, R.; ROCHE, M.M. Making value out of ethics: The emerging economic geography of lab-grown meat and other animal-free food products. Economic Geography, v. 95, n. 2, p. 136-158, 2019.

NIERENBERG, A. 2020. Plant-based "meats" catch on in the pandemic. Acesso: https://www.nytimes.com/2020/05/22/dining/plant-based-

meatscoronavirus.html?searchResultPosition=2 . Acesso dia 25, julho, 2020. 
OLIVEIRA, A. 2020. Foodtech brasileira Fazenda Futuro começa a exportar para Dubai. Acesso: https://www.sunoresearch.com.br/noticias/fazenda-futuro-comeca-exportar-dubai/, Acesso dia 25, julho, 2020.

ONG, S.; CHOUDHURY, D.; NAING, M.W. Cell-based meat: Current ambiguities with nomenclature. Trends in Food Science \& Technology, 2020.

Orlich, M.J.; Singh, P.N.; Sabaté, J.; Jaceldo-Siegl, K.; Fan, J.; Knutsen, S.; Beeson, W.L.; Fraser, G.E. 2013. Vegetarian dietary patterns and mortality in Adventist Health Study 2. JAMA Intern. Med., v.173. p. 1230-1238, 2013.

PINELI, L. L. O.; BOTELHO, R. B. A.; ZANDONADI, R. P.; SOLORZANO, J. L.; OLIVEIRA, G. T.; REIS, C. E.; TEIXEIRA, D. S. 2015. Low glycemic index and increased protein content in a novel quinoa milk. LWT - Food Science and Technology, v. 63. p. 1261-1267, 2015.

RAWAL, G.; YADAV, S.; NAGAYACH, M.S.. Phytosterols and the health. Medico Research Chronicles, v. 2, n. 3, p. 441-444, 2015.

REIPURTH, M.F.S.; HORBY, L.; GREGERSEN, C.G.; BONKE, A.; PEREZ CUETO, F.J.A. Barriers and facilitators towards adopting a more plant-based diet in a sample of Danish consumers. Food quality and preference, v. 73, p. 288-292, 2019.

REUTERS, 2020. Bife à base de plantas é produzido por impressora 3D em negócio de startup israelense. Acesso: https://g1.globo.com/bemestar/viva-voce/noticia/2020/06/30/bife-abase-de-plantas-e-produzido-por-impressora-3d-em-negocio-de-start-up-isralense.ghtml, Acesso dia 25, julho, 2020.

RINCON, L.; BOTELHO, R. B. A.; ALENCAR, E. R. 2020. Development of novel plantbased milk based on chickpea and coconut. LWT, v. 128. 109479, 2020.

RUBY, M. B. 2012. Vegetarianism: a blossoming field of study. Appetite, v.58. p. 141-150, 2012.

SÁNCHEZ-VIOQUE, R.; CLEMENTE, A.; VIOQUE, J.; BAUTISTA, J.; MILLÁN, F. 1999. MillánProtein isolates from chickpea (Cicer arietinum L.): Chemical composition, functional properties and protein characterization. Food Chemistry, v. 64. p. 237-243, 1999.

SARNI, A. R.; BARONI, L.. Milk and Parkinson disease: Could galactose be the missing link. Mediterranean Journal of Nutrition and Metabolism, v. 12, n. 1, p. 91-118, 2018.

SEBASTIANI, G.; BARBERO, A.H.; BORRÁS-NOVELL, C.; CASANOVA, M.A.; ALDECOA-BILBAO, V.; ANDREU-FERNANDEZ, V.; TUTUSAUS, M. P.; MARTINEZ, S.F.; ROIG, M.D.G.; GARCIA-ALGAR, O.. The effects of vegetarian and vegan diet during pregnancy on the health of mothers and offspring. Nutrients, v. 11, n. 3, p. 557, 2019.

SETHI, S.; TYAGI, S. K.; ANURAG, R. K. 2016. Plant-based milk alternatives an emerging segment of functional beverages: A review. Journal of Food Science and Technology, v.53. p. 3408-3423, 2016. 
SEXTON, A. E.; GARNETT, T.; LORIMER, J. 2019. Framing the future of food: The contested promises of alternative proteins. Environment and Planning E: Nature and Space, v. 0, p. $1-26$.

SHA, L.; XIONG, Y. L. 2020. Plant protein-based alternatives of reconstructed meat: Science, technology, and challenges. Trends in Food Science \& Technology, v. 102, p. 51 61.

SILVA, A.R.A.; SILVA, M.M.N.; RIBEIRO, B.D.. Health issues and technological aspects of plant-based alternative milk. Food Research International, v. 131, p. 108972, 2020.

SLADE, P. 2018. If you build it, will they eat it? Consumer preferences for plant-based and cultured meat burguers. Appetite, v. 125, p. 428 - 437.

SNOWDON, D.A.; PHILLIPS, R.L. Does a vegetarian diet reduce the occurrence of diabetes?. American journal of public health, v. 75, n. 5, p. 507-512, 1985.

TACO. Tabela brasileira de composição de alimentos. Campinas: NEPA- UNICAMP, 2011. 161 p. Disponível em : https://www.cfn.org.br/wpcontent/uploads/2017/03/taco_4_edicao_ampliada_e_revisada.pdf. Acesso em 20 julho 2020.

TRUSTS, P.C.; HOPKINS, J.. Putting meat on the table: Industrial farm animal production in America. A Report of the Pew commission on industrial Farm Animal Production, 2008. v. 22. p. 112-120, 2011.

VANGA, S. K.; RAGHAVAN, V. 2018. How well do plant based alternatives fare nutritionally compared to cow's milk? Journal of Food Science \& Technology, v. 55. p. 1020, 2018.

VASCONCELOS, I. M.; CAMPELLO, C. C.; OLIVEIRA, J. T. A.; CARVALHO, A. F. E.; SOUZA, D. O. B.; MAIA, F. M. M. 2006. Brazilian soybean Glycine max (L.) Merr. cultivars adapted to low latitude regions: seed composition and content of bioactive proteins. Brazilian Journal of Botany, v.29. p.617-625, 2006.

VISON, J. A.; CAI, Y. 2012. Nuts, especially walnuts, have both antioxidant quantity and efficacy and exhibit significance potential health benefits. Food Funct., v.3,. p.134-140, 2012.

WANG, F.; ZHENG, J.; YANG, B.; JIANG, J., FU, Y.; LI, D.. Effects of vegetarian diets on blood lipids: a systematic review and meta-analysis of randomized controlled trials. Journal of the American Heart Association, v. 4, n. 10, p. e002408, 2015.

WANG, S.; CHELIKANI, V.; SERVENTI, L. 2018. Evaluation of chickpea as alternative to soy in plant-based beverages, fresh and fermented. LWT, v. 97. p. 570-572, 2018.

YAFFE-BELLANY, D. 2020. The new makers of plant-based meat? Big meat companies. Acesso: https://www.nytimes.com/2019/10/14/business/the-new-makers-of-plant-based-meatbig-meat-companies.html/, acesso dia 25, julho, 2020. 